\title{
The role of induced set in figural after-effects'
}

\author{
Lorna Gaze and P. C. Dodwell \\ QUEEN'S UNIVERSITY
}

\begin{abstract}
Naive Ss do not report figural after-effects (FAE) reliably. Many experiments on FAE have used Ss who were aware of the expected outcomes. It is demonstrated that pseudo-FAEs can be induced readily in naive Ss, with appropriate set-inducing instructions, and the pseudoeffects can be obtained equally in the classically expected direction or in the opposite direction. Suggestible Ss tend to show greater pseudo-FAEs than non-suggestibles in some situations.
\end{abstract}

\section{Problem}

The classical study of visual FAE by Köhler \& Wallach (1944) has been widely accepted as a veridical study of an important perceptual phenomenon, and many subsequent investigators have reported that reliable replication is possible under a variety of conditions. On the other hand there is a number of reports extant (e.g., Weitz \& Compton, 1950; Duncan, 1958) claiming that FAEs cannot be obtained with naive Ss. A great many of the positive results have been obtained with psychologists as observers, who could be expected to have knowledge of the desired effect. In view of the well-known effects of set on a variety of perceptual phenomena, it seemed worth finding out to what extent differences in set might be responsible for differences in reports of FAE. Under an extreme positivistic hypothesis one might even claim that FAEs are nothing but set-induced pseudo-perceptual effects.

\section{Merhod}

Three hundred and thirty-five experimentally naive female students were tested with the Hull body-sway test. Suggestibility was measured by the difference between a control sway score and the score obtained when the $\mathrm{S}$ heard recorded suggestions that she was falling. ${ }^{2} \mathrm{~A}$ difference of 2 in or greater was used as a criterion of suggestibility, and $15 \%$ of the Ss exceeded this figure. Fifty suggestibles and 50 nonsuggestibles served as Ss.

The FAE stimuli are shown in Fig. 1. They were presented as sharp black shadows on a white transluscent semi-circular screen, radius $45 \mathrm{~cm}$. The fixation point was an annulus $.38^{\circ}$ in diameter and $.10^{\circ}$ wide centered on the screen. The bars making up the patterns were $0.64^{\circ} \times 6.40^{\circ}$. The peripheral displacement of the figures and the I-T distance could be varied.

The $\mathrm{S}$ sat with her head in a headrest with her right eye at the center of the semi-circle formed by the screen, and at the same height as the fixation mark. The extreme left-hand T-bar, which could be moved at the rate of $4^{\mathrm{O}}$ per second, was controlled by the $\mathrm{S}$ by means of a push button. The I and $\mathrm{T}$ figures could be inter-changed in less than $2 \mathrm{sec}$. without interrupting fixation. Monocular fixation with the right eye was used throughout. The $S$ was given 10 practice and 10 control adjustments of the T-figure starting about $18^{\circ}$ to the left of the point of actual equality each time. This was followed by 10 experimental trials in which adjustment of the $\mathrm{T}$-figure was preceded by 60-sec. fixation of the I-figure and followed by a 110-sec. rest period. An additional 10 control trials were given. Figural after-effects were scored as the difference between the means of the experimental and control readings. The $\mathrm{I}-\mathrm{T}$ distance was $0.1^{\mathrm{O}}$, found in a pre-test to give the largest (but non-significant) difference between control and experimental conditions.
The experiment was a $2 \times 2 \times 5$ factorial with suggestibility ( 2 levels) viewing conditions (central and peripheral) and suggestion (5 levels) as factors. Suggestion ranged from strong to weak positive, through zero, to weak and strong negative.

The $\mathrm{S}$ was assigned to a peripheral or foveal viewing condition and 10 practice and 10 control trials were given. The experimenter then left the room and an assistant assigned the $S$ to one of five set groups and gave the set-inducing instructions. The set was a "rational" explanation of the effect and its expected direction. The positive groups were told that fatigue, and hence repulsion, would cause the fixed bars to appear further apart than in the control condition, while the negative groups were told that warm-up and attraction would cause the fixed bars to appear closer together. The groups labelled "strong" received the added suggestion that the effect occurred primarily in people of high intelligence. The "zero" group received no instructions. The experimenter returned and gave the 10 experimental and the final block of 10 control trials.

\section{Results}

The findings are shown in Figs. 2 and 3. It is clear that set-inducing instructions have a large effect on the "perceived" FAE, of about equal magnitude for positive and negative set, and that the zero-set group show almost no effect at all. The effects are greater for peripheral than for central viewing conditions. The reliability of these results was assessed by analysis of variance.

The set effect was significant $(F=49.7$; df $(4,80)$; $\mathrm{p}<.001)$ although suggestibility and the set $\mathrm{x}$ suggestibility interaction were not. The only other significant source of variance was set $x$ viewing condition $(F=3.82$; df $(4,80) ; p<.01)$ showing that the set effect was more pronounced under peripheral (and hence more ambiguous) viewing conditions. It was predicted that the set $\mathbf{x}$ suggestibility interaction would be significant, since in a previous study of similar design, but with central view-

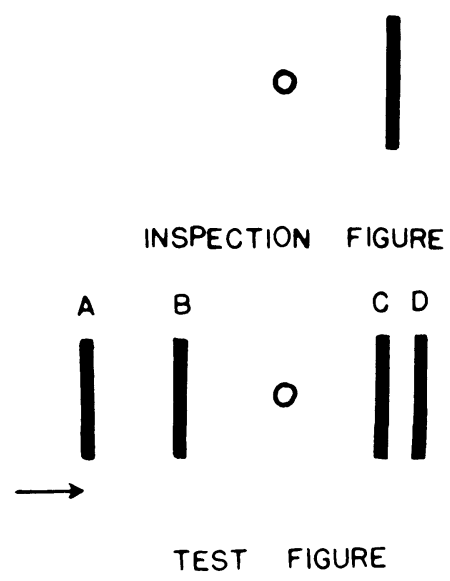

Fig. 1. Stimulus displays used to measure FAEs. Bar A of the test display is adjustable while bars B, C and D are fixed. 


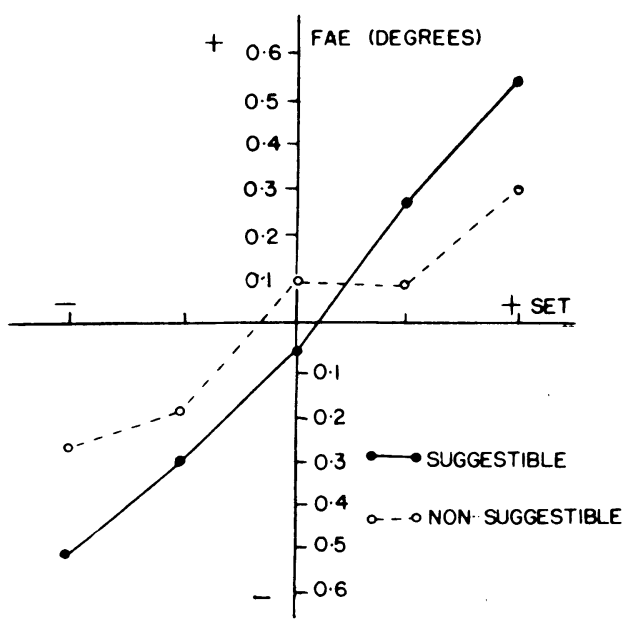

Fig. 2. FAEs as a function of set and suggestibility as found under the central $\left(4^{\circ}\right)$ viewing condition.

ing only $\left(4^{\circ}\right)$ the linear component of this interaction had been. In fact in the present experiment this component is also significant $(p<.05)$ if the data for central viewing only are considered. However not too much weight can be attached to this finding since neither the triple interaction of set $\mathbf{x}$ suggestibility $\mathbf{x}$ viewing nor its linear component is reliable.

Thus it can be said with some confidence that the size and direction of an FAE can readily be affected by an inducing set, and that the effect is greater under peripheral than central viewing conditions. The data suggest that the effect is greater for suggestibles under central viewing than for non-suggestibles, although this conclusion is not unambiguously supported.

The FAEs obtained under the "zero-set" condition were not significantly different from zero for either condition, but in every case the PSE was significantly greater than zero. It might be argued that the PSE could itself be contaminated by after-effects, since 10 control readings were taken after the experimental readings. That this was not so is indicated by the fact that the mean setting on the second set of control readings was actually less than that on the first set, and not significantly different from it.

\section{Diseussion}

Since many of the experiments on FAE have been performed on non-naive Ss, the results here reported seem to cast serious doubt on their validity. It is not claimed that there is no such thing as an FAE, only that many, if not most, of the reported studies are probably seriously contaminated by $\mathrm{S}$ expectations, and hence cannot be taken as true demonstrations of genuinely perceptual events. It is true that many perceptual phenomena may be influenced by set, but we know of none that is

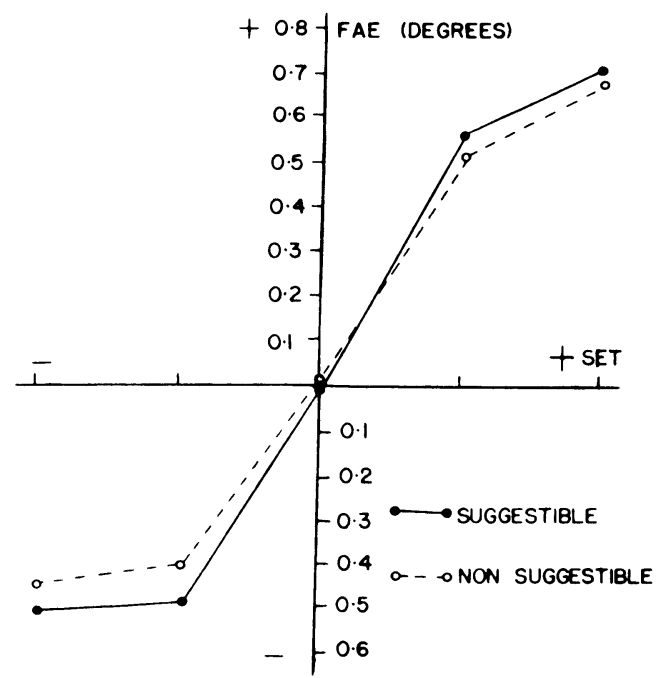

Fig. 3. FAEs as a function of set and suggestibility as found under the peripheral $\left(20^{\circ}\right)$ viewing condition.

accepted as genuine that (a) cannot be reliably obtained in naive Ss without set induction, and (b) can be made to occur in opposite directions with equal facility by the appropriate set induction.

It might be argued that we have used special stimulus conditions that do not produce FAEs but are particularly susceptible to manipulation by set. However, it should be noted that FAEs have been widely accepted as effects which will occur at any pair of neighboring contours viewed sequentially, so that even one negative finding would be of considerable theoretical importance. Negative results have been reported by others too, as previously noted, and we have also repeated the experiment with different stimuli but the same result (no FAE with naive $\mathrm{Ss}$ ). In conclusion, set has been shown to have large and consistent effects on the perception of FAEs in one particular apparatus, so that no report of FAEs should be accepted as reliable unless the precise conditions under which they were obtained-including the knowledge and expectations of the Ss-is accurately reported.

\section{References}

DUNCAN, C.P. Visual figural after-effects as a function of stimulation interval and decay time. Percept. mot. Skills, 1958, 8, 203-206. KÖHLER, W。, \& WALLACH, H. Figural after-effects. Proc. Amer. Phil. Soc., 1944, 88, 269-357.

WEITZ, J., \& COMPTON, B. A further stereoscopic study of figural after-effects. Amer. J. Psychol., 1950, 63, 78-83.

\section{Notes}

1. This research was supported by grant APA 44 from the National Research Council of Canada, to the second author, and by the Arts Research Committee of Queen's.

2. Falling, recorded by H.J. Eysenck, and obtainable from Star Sound Studios, Cavendish Square, London, England. 